\title{
The Perception of Emotional Intelligence Self-Assessment Among Nursing Students
}

\author{
Ghada Mohamed Hassan Hamouda ${ }^{1,}$, Elham Abdullah Helmi Al Nagshabandi, ${ }^{1,2}$ \\ ${ }^{1}$ Department of Nursing Administration, Faculty of Nursing, Alexandria University, Alexandria, Egypt \\ ${ }^{2}$ Department of Med-Surg. Nursing, Faculty of Nursing, King AbdulAziz University, Jeddah, Saudi Arabia
}

Email address:

Ghada_hamouda88@yahoo.com (G. M. H. Hamouda),Elham@kau.edu.sa (E. A. H. Al Nagshabandi)

${ }^{*}$ Corresponding author

\section{To cite this article:}

Ghada Mohamed Hassan Hamouda, Elham Abdullah Helmi Al Nagshabandi. The Perception of Emotional Intelligence Self-Assessment Among Nursing Students. American Journal of Nursing Science. Vol. 7, No. 5, 2018, pp. 173-177. doi: 10.11648/j.ajns.20180705.13

Received: June 20, 2018; Accepted: July 17, 2018; Published: September 15, 2018

\begin{abstract}
Emotional Intelligence is considered one of the main important skills in healthcare. Many higher institutions of nursing are interested in for improving nursing students' academic results by demonstrating emotional intelligence competencies. The aim of the study is to assess the perception of emotional intelligence self-assessment among nursing students. Accordingly, a quantitative and descriptive cross-sectional design was used in this study in which data was collected by distributing a questionnaire among nursing students $(\mathrm{N}=326)$ in the Faculty of Nursing, Alexandria University. The findings of the study revealed that the highest mean of nursing students was for social-emotional management, while the lowest mean was for emotional awareness. Also, there was a significant statistical difference between the perception of nursing students' emotional intelligence and their educational level. In conclusion, enhancing emotional intelligence skills among nursing students is essential for their academic performance as well as their profession. Hence, it should be introduced in the nursing curriculum to improve the quality of critical thinking to graduating in their fourth year including workshops to integrate the theoretical studies with clinical practice.
\end{abstract}

Keywords: Self Assessment, Emotional Intelligence, Nursing Students

\section{Introduction}

Emotional intelligence is an issue that can maintain one's life and make better adapt to different situations [1]. Emotional intelligence dimensions include emotional awareness, emotional management, social-emotional management and relationship management [2, 3].

Emotional awareness refers to the clearness of one's feelings, to what extent dose the person's moods impact on others, and it describes how the individual able to stand apart from his thoughts and feelings for examining them. Emotional management means people can accept responsibilities, set goals, be patient in accepting critical comments, and managing stressful situations. Also, creates ways to direct positive energy for work and hobbies. The third dimension is social-emotional management which contains the ability for making decision, understand and dealing with others' feelings to be supportive. Relationship management is the fourth dimension and it indicates how individual be sociable for motivating and helping others [3].

Skills of emotional intelligence are necessary for nurses and nursing profession that can affect the quality of their work including clinical decision-making, critical thinking [4]. Students need to coordinate their thoughts, feelings, and emotions in order to meet the requirements of a better and healthier life [1].

Nursing students are committed to link between theoretical learning and clinical nursing education by achieving ultimate goals such as: using nursing process, developing communication skills, enhancing clinical skills for safe interventions and considering ethical implications.... etc. Introducing EI characteristics to nursing students should support and facilitate attaining these goals. Important part of practice and achievement is to change students' perception toward EI [5].

Studies done on EI pointed that students' abilities or traits such as, critical thinking, leadership, ethical behavior, 
satisfaction and nursing student performance improved by using EI skills [6, 7]. Furthermore, Academic nursing students lack the competencies of both level emotionally and socially which in turn it is hindering their achievement [8]. It seems from the previous issue that nursing students are lacking practicing EI skills. Accordingly, introducing EI in education is promoting students' lifestyle, capabilities, emotional maturity and better psychological state.

\section{Material \& Methods}

\subsection{Research Design}

Quantitative, descriptive cross-sectional design was used.

\subsection{Setting}

The study was conducted in Faculty of Nursing, Alexandria University for nursing students in all academic years $(\mathrm{N}=326)$. Non-probability convenient sample was used.

\subsection{Tool}

Data was collected by using Emotional Intelligence SelfAssessment questionnaire adapted for the San Diego City College MESA Program from a model by Paul Mohapel, it includes 40 items, divided into four main dimensions, Emotional Awareness (10 items), Emotional Management (10 items), Social Emotional Management(10 items), and Relationship Management (10 items),. Each question was designed based on a 5-point Likert scale scoring from 0 to 4 $($ Never $=0$ to Always $=4)$.

\subsection{Statistical Analysis}

The data were analyzed using SPSS 22, descriptive statistics of the variables in the study included frequency, percentage, means, and standard deviations. The association between the variables was explored using Mann-Whitney and Kruskal-Wallis tests.

\section{Results}

Table 1. Socio-Demographic Characteristics of Nursing Students.

\begin{tabular}{|c|c|c|c|}
\hline Socio-Demographic characteristics & & Count & $\%$ \\
\hline \multirow{2}{*}{ Age } & $<20$ years old & 151 & $46.3 \%$ \\
\hline & 20 years old and more & 175 & $53.7 \%$ \\
\hline \multirow{2}{*}{ Gender } & Female & 194 & $59.5 \%$ \\
\hline & Male & 132 & $40.5 \%$ \\
\hline \multirow{3}{*}{ Educational Level } & First year & 89 & $27.3 \%$ \\
\hline & Second year & 79 & $24.2 \%$ \\
\hline & Third year & 77 & $23.6 \%$ \\
\hline \multirow{3}{*}{$\begin{array}{l}\text { Have you attended any workshop about Emotional } \\
\text { Intelligence? }\end{array}$} & No & 323 & $99.1 \%$ \\
\hline & Yes & 3 & $.9 \%$ \\
\hline & Total & 326 & $100.0 \%$ \\
\hline
\end{tabular}

Table 2. Total Mean and Standard Deviation Scores for Emotional Intelligence Dimensions.

\begin{tabular}{|c|c|c|c|c|c|c|c|c|c|}
\hline \multirow{2}{*}{ EI Dimensions } & \multicolumn{2}{|l|}{$\mathbf{N}$} & \multirow{2}{*}{ Mean } & \multirow{2}{*}{ Median } & \multirow{2}{*}{$\begin{array}{l}\text { Std. } \\
\text { Deviation }\end{array}$} & \multirow{2}{*}{ Skewness } & \multirow{2}{*}{ Kurtosis } & \multirow{2}{*}{ Minimum } & \multirow{2}{*}{ Maximum } \\
\hline & Valid & Missing & & & & & & & \\
\hline I- Emotional Awareness & 326 & 0 & 1.8337 & 1.7000 & .43376 & .644 & -.268 & .90 & 3.20 \\
\hline II- Emotional Management & 326 & 0 & 1.8488 & 1.7000 & .39905 & .574 & -.182 & .80 & 3.30 \\
\hline III- Social Emotional Management & 326 & 0 & 2.5163 & 2.4000 & .79689 & .158 & -1.373 & 1.00 & 3.80 \\
\hline IV- Relationship Management & 326 & 0 & 1.9325 & 1.7500 & .50045 & .585 & -.348 & .80 & 3.40 \\
\hline
\end{tabular}

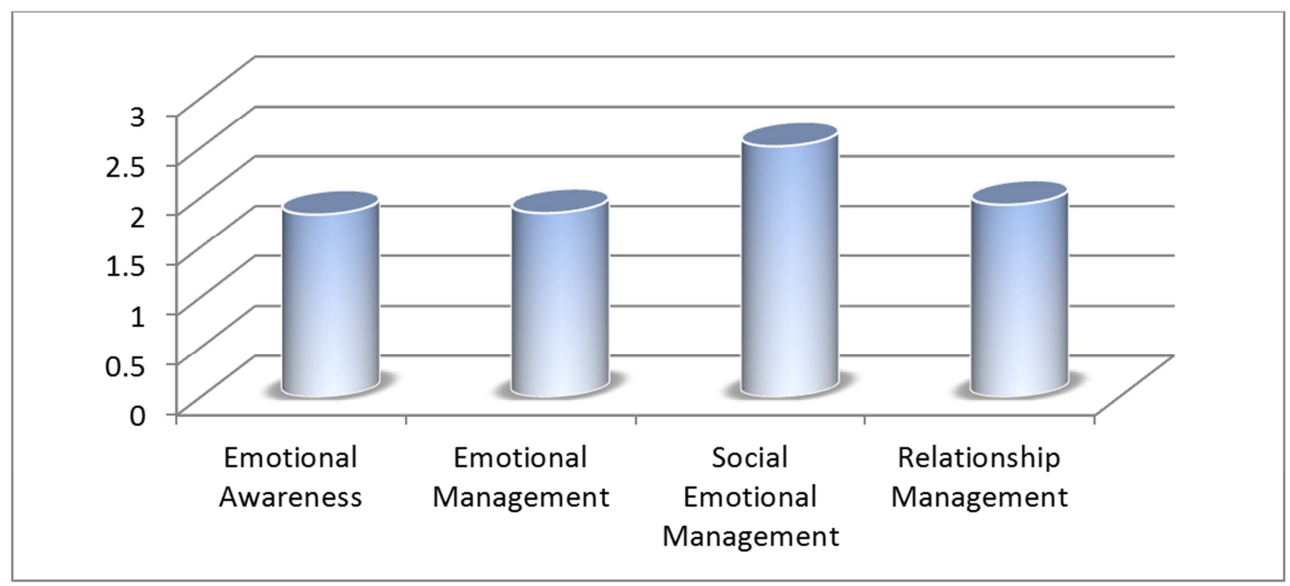

Figure 1. Total Mean Scores for Emotional Intelligence Dimensions. 
Table 3. Differences between Emotional Intelligence Dimensions and Nursing Students' Age.

\begin{tabular}{|c|c|c|c|c|}
\hline & Age & $\mathbf{N}$ & Mean Rank & Sum of Ranks \\
\hline \multirow[t]{2}{*}{ I- Emotional Awareness } & $<20$ years old & 151 & 146.44 & 22112.00 \\
\hline & 20 years old and more & 175 & 178.22 & 31189.00 \\
\hline \multirow[t]{2}{*}{ II- Emotional Management } & $<20$ years old & 151 & 137.14 & 20708.00 \\
\hline & 20 years old and more & 175 & 186.25 & 32593.00 \\
\hline \multirow[t]{2}{*}{ III- Social Emotional Management } & $<20$ years old & 151 & 109.34 & 16510.00 \\
\hline & 20 years old and more & 175 & 210.23 & 36791.00 \\
\hline \multirow[t]{3}{*}{ IV-Relationship Management } & $<20$ years old & 151 & 142.30 & 21487.50 \\
\hline & 20 years old and more & 175 & 181.79 & 31813.50 \\
\hline & Total & 326 & & \\
\hline Dimensions & Mann-Whitney U & Wilcoxon W & $\mathbf{Z}$ & Asymp. Sig. (2-tailed) \\
\hline I- Emotional Awareness & 10636.000 & 22112.000 & -3.052 & .002 \\
\hline II- Emotional Management & 9232.000 & 20708.000 & -4.720 & .000 \\
\hline III- Social Emotional Management & 5034.000 & 16510.000 & -9.654 & .000 \\
\hline IV- Relationship Management & 10011.500 & 21487.500 & -3.787 & .000 \\
\hline
\end{tabular}

Table 4. Differences between Emotional Intelligence Dimensions and Nursing Students' Gender.

\begin{tabular}{|c|c|c|c|c|}
\hline Gender & & $\mathbf{N}$ & Mean Rank & Sum of Ranks \\
\hline \multirow[t]{2}{*}{ I- Emotional Awareness } & Female & 194 & 178.94 & 34715.00 \\
\hline & Male & 132 & 140.80 & 18586.00 \\
\hline \multirow[t]{2}{*}{ II- Emotional Management } & Female & 194 & 178.19 & 34569.50 \\
\hline & Male & 132 & 141.91 & 18731.50 \\
\hline \multirow[t]{2}{*}{ III- Social Emotional Management } & Female & 194 & 165.99 & 32202.50 \\
\hline & Male & 132 & 159.84 & 21098.50 \\
\hline \multirow[t]{2}{*}{ IV- Relationship Management } & Female & 194 & 172.82 & 33527.50 \\
\hline & Total & 326 & & \\
\hline Dimensions & Mann-Whitney U & Wilcoxon W & $\mathbf{Z}$ & Asymp. Sig. (2-tailed) \\
\hline I- Emotional Awareness & 9808.000 & 18586.000 & -3.605 & .000 \\
\hline II- Emotional Management & 9953.500 & 18731.500 & -3.434 & .001 \\
\hline III- Social Emotional Management & 12320.500 & 21098.500 & -.580 & .562 \\
\hline IV- Relationship Management & 10995.500 & 19773.500 & -2.173 & .030 \\
\hline
\end{tabular}

Table 5. Differences between Emotional Intelligence Dimensions and Nursing Students' Academic Year.

\begin{tabular}{|c|c|c|c|}
\hline Educational Level & & $\mathbf{N}$ & Mean Rank \\
\hline \multirow{4}{*}{ I- Emotional Awareness } & 1st year & 89 & 116.07 \\
\hline & Second year & 79 & 258.85 \\
\hline & Third year & 77 & 197.43 \\
\hline & Fourth year & 81 & 90.37 \\
\hline \multirow{4}{*}{ II- Emotional Management } & 1st year & 89 & 103.11 \\
\hline & Second year & 79 & 266.25 \\
\hline & Third year & 77 & 186.06 \\
\hline & Fourth year & 81 & 108.19 \\
\hline \multirow{4}{*}{ III- Social Emotional Management } & 1st year & 89 & 46.78 \\
\hline & Second year & 79 & 169.49 \\
\hline & Third year & 77 & 176.67 \\
\hline & Fourth year & 81 & 273.39 \\
\hline \multirow{5}{*}{ IV- Relationship Management } & 1st year & 89 & 101.85 \\
\hline & Second year & 79 & 266.76 \\
\hline & Third year & 77 & 195.12 \\
\hline & Fourth year & 81 & 100.47 \\
\hline & Total & 326 & \\
\hline Dimensions & Chi-Square & df & Asymp. Sig. \\
\hline Emotional Awareness & 163.848 & 3 & .000 \\
\hline Emotional Management & 164.768 & 3 & .000 \\
\hline Social Emotional Management & 249.257 & 3 & .000 \\
\hline Relationship Management & 179.147 & 3 & .000 \\
\hline
\end{tabular}

In relation to nursing students' socio-demographic characteristics, the study revealed that the majority of them was female students, aged 20 years old and more 53.7\%, $59.5 \%$ respectively. Also, the majority $99.1 \%$ of them didn't 
attended workshop about emotional intelligence. Socialemotional management dimension had the highest mean score $2.51 \pm .79$, while the lowest mean score was for emotional Awareness $1.83 \pm .43$. In addition, the same dimension had the highest mean score for nursing students' perception in both categories students had 20 years old and more and students who registered in the third academic year, 210.23 and 273.39 respectively. While, as for students' gender, the results found that female students perceiving higher emotional awareness and emotional management 178.94, 178.94 than male students that indicates positive statistical significant difference where $\mathrm{P}$ value $=0.000$ and 0.001 respectively. While, there was no statistical significant difference between male and female students regarding social-emotional management $\mathrm{P}=0.562$.

\section{Discussion}

Older students showed a positive relationship with emotional intelligence skills and peer interaction [9]. Also, it was mentioned that there was a significant increase in managing self and other emotions with students in high academic year, this is because of the emotional balance as a result of exposing to stressful situations which enable them to handle it more flexible, supportive and planned [10]. In the same line, it was concluded that emotional intelligent behaviors are effective to manage stressful interpersonal interactions [11]. This is in contrast with another research which stated that emotional intelligence was not a useful indicator of performance [12]. Moreover, it was added that there is no relationship between emotional intelligence of students and their academic achievements [13, 14].

There was an important link between leadership behaviors and emotional intelligence in order to promote ongoing sensible, safe and high-quality care [15]. An in-depth clarification showed that the servant-leadership style enhances emotional intelligence, which is visible in nursing students' self-relationship, as well as working in team and that students' clinical communication abilities had positive relation with emotional intelligence $[16,17]$. Moreover, other researchers have highlighted the significance of collegial relationships and organizational support and supervision, and its relation to students' emotional labour and the degree of cooperation [18].

The current study revealed that there was a positive relationship between female nursing students and their perception toward emotional intelligence dimensions. However, there were conclusions that genders have no relationship with emotional intelligence, social skills and self-efficacy [13]. In contrast, some findings informed that the chance of participation to have a positive relationship with emotional intelligence of male students whereas it was not associated with the emotional intelligence of female students [13]. Regardless of a student's gender, it is concluded that a supportive environment has positive relationship with emotional intelligence.

As for the importance of attending workshops or training for improving EI skills, the results showed that approximately all the students did not attend neither training programs nor workshops about EI. In relation to this, emotional intelligence should be given more importance in nursing education, students demonstrated in their trainings on controlling emotions, it may enhance their practice in clinical environment [20]. The results are inconsistent with another researcher who studied first year nursing students and the effect of training program on their level of emotional intelligence. It was found that the training program had no effect, in addition, the students felt no need to learn emotional intelligence skills although they have no clinical experience [21]. While there were others who suggested training nursing students about emotional intelligence for improving healthy behaviors [22].

\section{Conclusion}

The results found that the highest mean score of all EI dimensions was for social-emotional management for older nursing students studied in the third academic year. Female students had the highest mean score in emotional awareness and emotional management dimensions. While, students in the first academic year had the lowest mean score of both previous dimensions. The majority of nursing students either male or female did not attend any EI workshop. Enhancing emotional intelligence skills among nursing students are essential for their performance as well as nursing profession. Therefore, enhancing emotional intelligence skills among third year were found specifically useful in buffering encountered stress and coping with academic and clinical day to day faced-by stressors. EI has also cultivated effective verbal and written communication which improves the overall nursing performance.

\section{Recommendations}

The study results recommended 1. Introducing emotional intelligence dimensions in nursing curriculum to improve the quality of their critical thinking. 2. Attending workshops and training programs for nursing students in order to integrate the theoretical studies with clinical practice, also for promote emotional balance. 3. Inform faculty members for applying EI skills to be role model for the students. 4. Continuous supervision and assessment from faculty members for providing proper guidance. 5. Increase the level of awareness for students' relatives such as family members about EI skills.

\section{References}

[1] Bar-on R. Parker JDA. The handbook of emotional intelligence: Theory, Development, Assessment, and Application at home, school and in the workplace. San Francisco: Jossey-Bass - Hardback; 2000.

[2] Jalali, SA. Emotional Intelligence. Quarterly of Education. 2002; 18(1\&2): 89-105. 
[3] Mohapel P. The quick Emotional Intelligence SelfAssessment. San Diego City College MESA Program. Paul.mohapel@shaw.ca.2015

[4] Queen, MC. Emotional intelligence in nursing work. Journal of Advanced Nursing. 2004; 47(1): 101-108.

[5] Jones \& Bartlett Learning, LLC. Goals of clinical nursing education. 2015, P1-22.

[6] Hall JA, Rosenthal R. Interpreting and evaluating metaanalysis. Eval Health Prof 1995; 18:393-407.

[7] Rosenthal R DiMatteo MR. Meta-analysis: Recent developments in quantitative method for literature reviews. Annu Rev Psychol 2001; 52:59-82.

[8] Manjusha, S., Dr. Soja, S. L., Dr. Usha, V. K. Emotional Intelligence and academic performance among nursing students. International Journal of Current Research. 2017; 03(9):48116-8.

[9] Balluerka N, Gorostiaga A, Alonso-Arbiol I, Aritzeta A. Peer attachment and class emotional intelligence as predictors of adolescents' psychological well-being: A multilevel approach. J Adolesc. 2016 Dec; 53:1-9.

[10] Foster K, Mc Cloughen A, Kefalas C, Harkness E. Nursing Education Today, 2015 Mar; 35(3):510-517.

[11] McCloughen A1, Foster K. Nursing and pharmacy students' use of emotionally intelligent behaviors to manage challenging interpersonal situations with staff during clinical placement: A qualitative study. J Clin Nurs. 2017 Apr 20.

[12] Stenhouse R1, Snowden A2, Young J2, Carver F2, Carver H2, Brown N2. Do emotional intelligence and previous caring experience influence student nurse performance? A comparative analysis. Nurse Educ Today. 2016 Aug; 43:1-9.

[13] Landau J., Meirovich G. (2011). Development of Students' Emotional Intelligence: Participative Classroom Environments in Higher Education. Academy of Educational Leadership Journal, 15, 3 .
[14] O'Connor Jr., Little, I, S. (2003). Revisiting the Predictive Validity of Emotional Intelligence: Self-Report Versus Ability-Based Measures. Personality and Individual Differences, 35, 893-1902.

[15] Carragher J, Gormley K. Leadership and emotional intelligence in nursing and midwifery education and practice: a discussion paper. J Adv Nurs. 2017 Jan; 73(1):85-96.

[16] [16] Anderson D. Servant Leadership, Emotional Intelligence: Essential for Baccalaureate Nursing Students. Creat Nurs. 2016 Aug 1; 22 (3):176-180.

[17] Kong L, Liu Y, Li G, Fang Y, Kang X, Li P. Resilience moderates the relationship between emotional intelligence and clinical communication ability among Chinese practice nursing students: A structural equation model analysis. Nurse Educ Today. 2016 Nov; 46:64-68.

[18] Riley R, Weiss MC. A qualitative thematic review: emotional labour in healthcare settings. J Adv Nurs. 2016 Jan; 72(1):617 .

[19] Salavera et al, Emotional intelligence and social skills on selfefficacy in Secondary Education students: Are there gender differences? Journal of Adolescence 2017 July; 60: 39-46.

[20] Barkhordari M, Rostambeygi P. Emotional intelligence in nursing students. Journal of Advances in Medical Education and Professionalism, 2013; 1(2): 46-50.

[21] Orak RJ, Farahani MA, Kelishami FG, Seyedfatemi N, Banihashemi S, Havaei F. Investigating the effect of emotional intelligence education on baccalaureate nursing students' emotional intelligence scores. Nurse Educ Pract. 2016 Sep; 20:64-9.

[22] Lana A, Baizán EM, Faya-Ornia G, López ML. Emotional Intelligence and Health Risk Behaviors in Nursing Students. J Nurs Educ. 2015 Aug; 54(8):464-7. 